Review

\title{
Photochemical Production of Interpenetrating Polymer Networks; Simultaneous Initiation of Radical and Cationic Polymerization Reactions
}

\section{Jean Pierre Fouassier ${ }^{1,2}$ and Jacques Lalevée ${ }^{1, *}$}

1 Department of Chemistry, University of Haute Alsace, Mulhouse 68057, France;

E-Mail: jp.fouassier@uha.fr

2 Institut de Science des Matériaux de Mulhouse IS2M, UMR CNRS 7361, UHA, 15, rue Jean Starcky, 68057 Mulhouse Cedex, France

* Author to whom correspondence should be addressed; E-Mail: jacques.lalevee@uha.fr; Tel.: +33-38-9608-803; Fax: +33-38-9608-800.

External Editor: Alexander Böker

Received: 2 September 2014; in revised form: 5 October 2014 / Accepted: 13 October 2014 / Published: 20 October 2014

\begin{abstract}
In this paper, we propose to review the ways to produce, through photopolymerization, interpenetrating polymer networks (IPN) based, e.g., on acrylate/epoxide or acrylate/vinylether blends and to outline the recent developments that allows a one-step procedure (concomitant radical/cationic polymerization), under air or in laminate, under various irradiation conditions (UV/visible/near IR; high/low intensity sources; monochromatic/polychromatic sources; household lamps/laser diodes/Light Emitting Diodes (LEDs)). The paper illustrates the encountered mechanisms and the polymerization profiles. A short survey on the available monomer systems and some brief examples of the attained final properties of the IPNs is also provided.
\end{abstract}

Keywords: interpenetrating polymer networks; radical initiators; photopolymerization; photoinitiators 


\section{Glossary of Terms}

\begin{tabular}{ll}
\hline Light Emitting Diode & LED \\
Interpenetrating polymer networks & IPNs \\
Semi-interpenetrating polymer networks & SIPN \\
Hexanediol diacrylate & HDDA \\
3,4-epoxycyclohexylmethyl-3'4' epoxycyclohexyl carboxylate & EPOX \\
Trimethylolpropane triacrylate & TMPTA \\
Tri(ethylene glycol) divinyl ether & DVE-3 \\
4-cyclo-hexane dimethanol divinyl ether & CHVE \\
diglycidyl ether of bisphenol A based epoxy resin & EP \\
Poly(ethylene glycol) diacrylate & PEGDA \\
Photoinitiating systems & PIS \\
Diphenyliodonium salts & DPI \\
Triarylsulfonium salts & TAS \\
Cationic Polymerization & CP \\
Free Radical Polymerization & FRP \\
Photoinitiating system & PIS \\
Photoinitiator & PI \\
\hline
\end{tabular}

\section{Introduction}

Interpenetrating polymer networks (IPNs) consist in two or more chemically different networks which are at least partially interlaced on a polymer scale but, in theory, are not covalently bonded to each other, although in practice some type of grafting between the networks invariably occurs. One can also define: (i) semi-interpenetrating polymer networks SIPN (they contain networks and linear or branched polymer(s) that can be separated) and (ii) sequential semi-interpenetrating polymer networks. IPNs and SIPNs can be formed simultaneously or sequentially [1-5]. All these arrangements belong to hybrid systems (systems that contain two or more different chemical functionalities) and lead to novel properties resulting from the physico-chemical nature of the monomer/polymer used and the degree of phase separation, the formed polymers being not miscible.

IPNs have applications, e.g., as sound- and vibration-damping materials over a broad temperature and frequency range (IPNs often result in a 10-100 $\mathrm{nm}$ finely-dispersed phase but, when the micro-heterogeneous phase domains are in the 10-20 nm range, the glass transition is relatively broad and leads to materials that can absorb energy), in impact resistant materials, toughened plastics, membranes, ion-exchange resins, $\mathrm{pH}$-sensitive systems, electrical insulation, coatings and encapsulants, adhesives, bearers of medicines, biomedical purposes, hydrogels, and materials for optics.

IPNs are synthesized from a blend of two multifunctional monomers that polymerize through two different routes (e.g., radical and cationic). This usually occurs according to a thermal process. On the other hand, photopolymerization techniques (as extensively described in [6-17]) are very well known for applications in various areas. They have also been proposed to produce IPNs, the environmentally-friendly character of this process (no volatile organic compounds released, room temperature operation, energy saving), the high polymerization rates attained under relatively intense UV irradiation and the easy triggering of the reaction (light on/off) being the main practical advantages [18]. 
A photoinitiating system (PIS) containing at least one or two photoinitiators PI is used to start the polymerization reactions (see below).

In this paper, as a matter of introduction, we will provide a short survey on the examples of available monomer blends suitable for the manufacture of IPNs under light exposures as well as some brief examples of the final properties of the IPNs that can be attained. Then, considering mostly acrylate/epoxide or acrylate/(di)vinylether blends as the starting materials, we will recall the different strategies for getting the photopolymerization reaction (one-step or two-step procedures) and stress again the traditional use of high intensity UV sources. We wish to focus the paper, however, on the particular recent research developments that open novel possibilities for the synthesis of IPNs as they allow a concomitant radical/cationic polymerization through an easy one-step (simultaneous) procedure under various irradiation conditions in term of lights (near UV/visible/near IR wavelength ranges, high/low intensity; monochromatic/polychromatic illumination) and irradiation devices (household lamps and light emitting diode (LEDs), laser diodes, LEDs for industrial applications). The reaction mechanisms as well as the achieved polymerization performance will be detailed.

\section{Monomers for the Manufacture of IPNs through Photopolymerization}

Various monomer blends have been applied for the manufacture of IPNs. Different examples can be given: acrylate/epoxide, (e.g., hexanediol diacrylate (HDDA)/3,4-epoxycyclohexylmethyl-3'4' epoxycyclohexyl carboxylate (EPOX)), trimethylolpropane triacrylate (TMPTA)/EPOX, TMPTA/diglycidyl ether of bisphenol A based epoxy resin EP, TMPTA/tri(ethylene glycol) divinyl ether (DVE-3), TMPTA/4-cyclo-hexane dimethanol divinyl ether (CHVE), fluorinated acrylate/epoxide, vinylether/acrylate, vinylether/maleate, vinylether/maleimide or oxetane/acrylate blends, (see e.g., in [19-35]) anthracene-labeled polystyrene/methyl methacrylate MMA/ethylene glycol dimethacrylate [36], polyisobutene/polystyrene [37], polyacrylate/polybenzoxazine [38], acrylic/liquid crystals [39,40], 2-hydroxyethyl methacrylate/ $N$-vinyl-2-pyrrolidone [41], polyurethane/poly(2-hydroxyethyl methacrylate) [42], calcium alginate/dextran-HEMA [43].

The photopolymerization of bisphenol- $A$-diglycidyl dimethacrylate/bisphenol- $A$-diglycidylether/tetrakis (methacryloxy ethoxy) silane [44,45], siloxane or silsesquioxane/ $\alpha, \omega$-nonconjugated dienes [46] leads to organic-inorganic IPNs. It should be noted that tetrakis (methacryloxy ethoxy) silane only forms an inorganic material after hydrolysis.

Semi-interpenetrating polymer networks have also been obtained by UV curing of, e.g., acrylate monomers dispersed in a polymer matrix (polyurethane, polyvinyl chloride, polymethyl methacrylate, polybutadiene, polyisoprene) [47], hyaluronic acid/hydroxyethyl methacrylate derivatized dextran (usable in 3D hydrogel bioprinted constructs) [48]. IPNs from acrylate/epoxidised polyisoprene blends have been reported [49].

IPNs have been prepared, e.g., from a trifunctional thiol/poly (ethylene glycol) (PEG)-diallyl blend via a thiol-ene coupling reaction [50].

A mixture of poly (ethylene glycol) diacrylate (PEGDA) and hexanediol diacrylate (HDDA) monomers polymerized within a hexagonal liquid crystalline template may form an IPN-type material [51]. Other systems where the characteristics or the properties in term of IPNs are not (totally) established have been only described as (i) hybrid polymers, e.g., materials derived from a thiol-ene and cationic 
polymerization using two Photoinitiators (PIs) [52] or one PI [53], cycloaliphatic epoxide/acrylate monomers [54-57], 3,4-epoxy-cyclohexyl-methyl methacrylate hybrid monomers [58], multifunctional glycidyl ether (or 3,3-disubstituted oxetane)/acrylate blends [59], thiol-epoxy/thiol-acrylate hybrids [60] or (ii) dual cure systems (they contain two or more different functionalities that polymerize using two different curing processes such as thermal/photochemical or photochemical/air drying), e.g., polymers formed from a glycidyl methacrylate/trimethylolpropane oxetane/acrylate blend [61].

Although most of works are carried in film matrix, other media can be used such as microemulsions [62]. Some kinetic studies on the photoinduced quasi-simultaneous IPN synthesis have been published [63-65]. Structure-property relationships in acrylate/epoxy IPNs have been investigated as a function of the reaction sequence and composition (the relationships between phase morphology, processing and physical properties of the IPNs are claimed as complex and not predictable a priori) [66].

\section{Examples of Final Properties for Photochemically Produced IPNs}

The monomer composition has a great importance in controlling the final conversion and the glass transition temperature of the polymer. The photocuring sequence and mode affect the final resin conversion and the morphology of the final material. Light induced polymerization of monomer blends have led to IPNs exhibiting interesting tailor-made properties. Some examples are shown here.

A high-damping effect, a lower shrinkage and a better adhesion was noted in acrylate/epoxide IPNs [28]. The reduction of the shrinkage limits the buildup of the internal stress and improves the adhesion. For example, the percentage shrinkage is $89.89 v s$. -13.25 and the adhesion tape is $100 \%$ vs. $0 \%$ for HDDA/EPOX (50/50) and HDDA, respectively (100\% adhesion for EPOX alone) [28]. Broad $T_{\mathrm{g}}$ peaks are observed: 153, 140 and $190{ }^{\circ} \mathrm{C}$ for HDDA/EPOX, HDDA and EPOX, respectively. Low shrinkage materials are of interest in applications where length variation should be avoided as far as possible (e.g., in 3D modelling, preparation of composites or in the manufacture of optical elements). In the same way, a reduced volume shrinkage in holographic photopolymers based on organic/inorganic hybrid IPNs [67] was achieved; thiol-ene/thiol-epoxy hybrid networks [68] led to a significantly reduced shrinkage and stress, a highly crosslinked and high $T_{\mathrm{g}}$ polymer as well as robust mechanical properties.

High surface hydrophobicity for the films together with good adhesion properties can be obtained on polar substrates. This is exemplified [68] by the observed contact angles (water; $110^{\circ}, 78^{\circ}$ and $115^{\circ}$ ) for the EP/fluorinated acrylate (FA) (50/50) IPN, EP and FA, respectively.

Both hardness and flexibility have been obtained in IPNs for coating applications [29]. Persoz hardness of $300 \mathrm{~s}$ can be reached. For example, IPNs that combine a stiff and glassy polyacrylate with a highly flexible and elastomeric polyvinylether are well adapted for applications where an ultrafast process and specific properties (hardness, elasticity and chemical resistance, etc.) are required.

Interesting extracting properties, e.g., selective solid phase extraction of $\mathrm{Cd}^{2+}$ with ion-imprinted IPN gel [69] and enhanced heavy metal ion removal [70] have been mentioned. Spatially graded morphology was shown in polystyrene/poly (methyl methacrylate) IPNs [71].

Hydrogels have received a considerable attention for use in tissue engineering scaffolds (with gelatin methacrylamide/PEG [72], silk fibroin/poly(vinyl alcohol) [73], silk fibroin/gelatin [74] or others [75]), cartilage tissue engineering (with poly (ethylene glycol)/agarose [76]), vascular tissue 
engineering (dextran/gelatin [77]). Mechanically enhanced properties (e.g., Young's moduli) rivaling those of natural load-bearing tissues was found in a poly (acrylic acid)/end-linked poly (ethylene glycol) crosslinked material [78]. A larger domain of tensile modulus (192-889 kPa compared to 175-555 kPa for single corresponding networks) [50] can be covered in systems used as scaffolds for the preparation of hydrogels. Poly (ethylene glycol)/poly (acrylamide) hydrogels can serve as a support of enzyme immobilization [79]. The polymerization of amphiphilic hydrogels under visible and UV light is interesting as the process conditions are very mild and the reaction can be carried out in direct contact with drugs, cells and tissues. Injectable hydrogels provide an effective and convenient way to administer a wide variety of bioactive agents such as proteins, genes, and even living cells [80]. Drug delivery purposes can be achieved with e.g., poly ( $N$-isopropylacrylamide)-modified poly(2-hydroxyethyl acrylate) hydrogels [81], poly (ethylene glycol)-co-poly (e-caprolactone) diacrylate macromer and hydroxypropyl guar gum [82]. A recent review on the design and the applications of IPN hydrogels has been published [83].

The high stiffness, the ultimate strength and strain, and the high stability of methacrylic alginate IPN gel beads are highly useful in designing encapsulation devices with improved structural durability for a broad array of prokaryotic and eukaryotic cells used in biochemical and industrial applications [84]. Photopolymerization provides a unique way to form an IPN gel in a fast and controllable manner usable for the direct photoencapsulation of cells. Gels can be formed in situ, providing an easy in vivo placement that can be of benefit for applications in tissue engineering. Photopolymerization can also be used to create scaffolds with specific nanoscale topography to promote control of cell migration and function [85].

Among other properties of UV produced IPNs, one can cite biocidal properties using a poly(ethylene terephthalate)/polyamide IPN [86], durable hemocompatibility [87], shape-memory properties (e.g., strain fixity rate and strain recovery rate above 93\% using polyesterurethane/poly (ethyleneglycol) dimethacrylate IPNs; the hydrophilicity, transition temperatures and mechanical properties of the IPNs can be easily adjusted through the network compositions so that promising potential clinical or medical application are expected [88], bioactivity (corneal epithelial wound healing) [89], using fibrin-polyethylene oxide IPNs [90], construction of multilayer ultrathin films (with poly (vinylpyrrolidone)/poly (urushiol) [91]), gradient property in polyurethane/ poly(2-hydroxyethyl methacrylate semi-IPNs usable in biomedical applications [92].

Photochemically synthesized IPNs can also be used in the generation of nanostructures [93,94], as $\mathrm{p}$ and $\mathrm{n}$ dopable films for organic photovoltaic devices [95], in the surface modification of polyethylene terephthalate angioplasty balloons (hydrophilic poly (acrylamide-co-ethylene glycol) IPN coating [96]), for cell adhesion and proliferation in vitro allowing a robust biomaterial (poly (ethylene glycol)/collagen IPNs) for elastomeric tissue scaffold applications [97], in dentistry (for getting teeth protection from acid demineralization [98] or the reinforcement of restorative composites [99]).

\section{Short Backgrounds on PIs and PISs}

The practical efficiency of a PIS in polymerization reactions under given experimental conditions is expressed in terms of polymerization rate $R_{\mathrm{p}}$ and final conversion. It depends on (i) the amount of absorbed light $I_{\text {abs }}$ which is a function of both the absorption properties of the PI (wavelengths $\lambda$ 
and molar extinction coefficients $(\varepsilon)$ and the intensity $I_{0}$ of the light source and (ii) the photochemical/chemical reactivity of the PIS (expressed by the initiation quantum yield $\Phi_{i}$ that depends on the encountered excited state processes); for example, in a radical photopolymerization, $R_{\mathrm{p}}$ is proportional to the square root of $\Phi_{\mathrm{i}} I_{\text {abs }}$ (for systems which have bimolecular termination such as most radical polymerizations) [100]. Therefore, a high efficiency of a given system is connected with high $\Phi_{\mathrm{i}}$ and $I_{\text {abs. }}$ However, a low $\Phi_{\mathrm{i}}$ and a high $I_{\mathrm{abs}}$ can lead to the same performance as a high $\Phi_{\mathrm{i}}$ and a low $I_{\text {abs. }}$ Improving the reactivity $\left(\Phi_{\mathrm{i}}\right)$ and designing PISs with better absorption properties $(\lambda, \varepsilon)$ leads to enhanced polymerization efficiencies and provides the possibility to use lower light intensities $I_{0}$.

Examples of usual radical PIs are cleavable compounds that undergo a fast breaking of a $\mathrm{C}-\mathrm{P}$ (in phosphineoxide derivatives such as phosphineoxide (TPO) or a $\mathrm{C}-\mathrm{C}$ bond (in hydroxyalkyl ketones such as hydroxyacetophenone (HAP)) as shown in Scheme 1 [100-103]. Widely used cationic photoinitiators are iodonium (DPI) and sulfonium (TAS) salts (Scheme 2) [100,102].

Scheme 1. Usual Type I photoinitiators (e.g., HAP, TPO), R stands for a phenyl ring in TPO and a methyl group in HAP.<smiles>[R]C(O)C(=O)c1ccccc1</smiles>

HAP

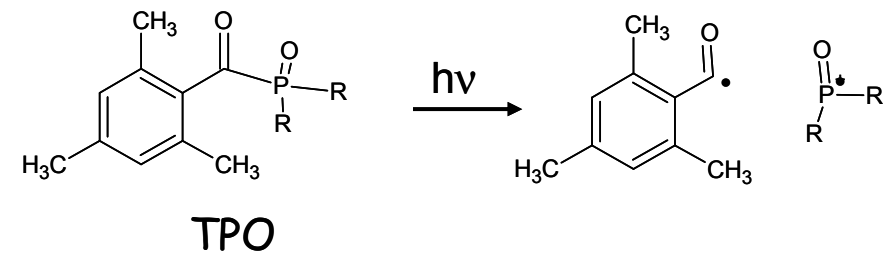

Scheme 2. Examples of Cationic Initiators (iodonium and triarylsulfonium TAS).

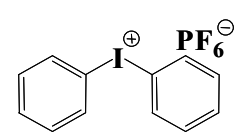

Iod

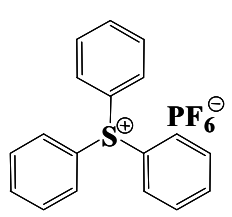

TAS

\section{Photochemical Production of IPNs: Mechanisms}

\subsection{Intense UV Light Exposure}

The main advantage of using UV lights in the polymerization of IPNs is the high polymerization rates that can be reached under usual $\mathrm{Hg}$ sources allowing an intense UV rich polychromatic illumination. The main drawback is the harmful character of the UV B and UV C rays delivered by these lamps. The photoinitiating system can consist in one or two PI that can be simultaneously or sequentially excited. 


\subsubsection{One-Photoinitiator Containing System}

An example relates to the use of diphenyliodonium salts DPI $\left(\mathrm{Ph}_{2} \mathrm{I}^{+}\right)$or triarylsulfonium salts TAS $\left(\mathrm{Ph}_{3} \mathrm{~S}^{+}\right)$that are able to generate both free radicals and protonic acids (Scheme 3). This requires an excitation at $254 \mathrm{~nm}$ (DPI) or 254/313 nm (TAS) and a high intensity as these systems are not extraordinarily reactive to initiate both a radical and a cationic polymerization. This strategy has been applied to the synthesis of, e.g., semi-IPNs from an EP/acrylated urethane oligomer blend using TAS under the intense UV light of a mercury lamp [104].

Scheme 3. Reaction sequence for cationic initiators.

$$
\begin{aligned}
& \mathrm{Ph}_{2} \mathrm{I}^{+} \rightarrow{ }^{1} \mathrm{Ph}_{2} \mathrm{I}^{+*}(\mathrm{~h} v) \rightarrow{ }^{3} \mathrm{Ph}_{2} \mathrm{I}^{+*} \\
& { }^{10 r 3} \mathrm{Ph}_{2} \mathrm{I}^{+*} \rightarrow \rightarrow \rightarrow \mathrm{Ph}-\mathrm{PhI}+\mathrm{PhI}+\mathrm{Ph} \bullet+\mathrm{H}^{+} \text {(in-cage and out-of-cage processes) } \\
& { }^{1}{ }^{\text {or }} \mathrm{Ph}_{3} \mathrm{~S}^{+} \rightarrow \rightarrow \rightarrow \mathrm{Ph}-\mathrm{PhS}-\mathrm{Ph}+\mathrm{Ph}_{2} \mathrm{~S}+\mathrm{Ph} \bullet+\mathrm{H}^{+} \text {(in-cage and out-of-cage processes) }
\end{aligned}
$$

Another example concerns the photopolymerization of a vinylether/acrylate blend [47]. When exposed to UV light ( $\mathrm{Hg}$ lamp, $50 \mathrm{~mW} / \mathrm{cm}^{2}$ ), the 1/1 mixture of DVE-3 and TMPTA in the presence of $2 \mathrm{wt} \%$ TAS readily polymerizes: almost $100 \%$ conversion for both the vinylether and the acrylate are reached within a few seconds. This unusual high conversion of TMPTA was attributed to a plasticizing effect of the cationic monomer. Other examples can be found, e.g., in [53].

\subsubsection{Two-Photoinitiator Containing Systems and One-Step Exposure}

In that case, two PIs are introduced into the formulation. For example, a radical PI such as HAP and a cationic PI such as TAS (concentrations: $2 \mathrm{wt} \%$ ) allow the photopolymerization of a HDDA/EPOX blend (100 $\mu \mathrm{m}$ thick) under a $\mathrm{Hg}$ lamp in air (very high intensity: $\left.350 \mathrm{~mW} / \mathrm{cm}^{2}\right)$ [28]. Free radicals originate from the photolysis of HAP (Scheme 1); protons are formed during the photolysis of TAS (Scheme 3). Conversions of $80 \%$ (HDDA) and 50\% (EPOX) at $t=120 \mathrm{~s}$ are reached.

Various UV-initiated polymerizations of TMPTA/EPOX, urethane acrylate/CHVE, TMPTA/CHVE blends in the presence of 1-hydroxy-cyclohexyl-phenyl ketone HCAP (it works as HAP) and DPI were also observed; the addition of isopropylthioxanthone (ITX) enhances the rate of polymerization and the surface curing; acrylates polymerize faster than epoxides and vinylethers [24]. Other examples can be found, e.g., in $[44,61]$.

In the same way, using HAP and TAS, a blend of HDDA and a renewable epoxy monomer (epoxidized soybean oil ESO (50:50) exposed to an intense UV illumination $\left(600 \mathrm{~mW} / \mathrm{cm}^{2}\right)$ was cured in less than $3 \mathrm{~s}$ under air (conversions: HDDA 100\%, ESO 80\%) [29]. A HDDA/EP based IPN can also be obtained in the presence of HCAP and DPI [29]. The oxygen inhibition of the radical polymerization is reduced here as (i) the high photon flux generates a high amount of radical initiating species and (ii) the early buildup of the epoxy network leads to a strong increase of the viscosity and slows down the diffusion of oxygen into the sample (which thereby reduces the scavenging of the free radicals and the formation of peroxyls). 


\subsubsection{Sequential Production of IPNs Using Two Different Lights}

Photoinitiation for the synthesis of IPNs has the unique advantage to also allow a sequential build-up of the two polymer networks. This can be achieved by a proper selection of the photoinitiators and the irradiation wavelengths (see a review on early experiments in [29] and references therein). The two PIs should be excited in two different wavelength ranges where the absorption spectra must have a minimum of overlap. Due to (i) the absorption of both PIs in the short UV wavelengths and (ii) the additional absorption of the radical PI in the near UV-visible part of the spectrum, one has to start first the polymerization of the acrylate under a filtered light. To avoid the oxygen inhibition (see above), high light intensities or/and viscous matrixes have to be used. For example, an acrylate/epoxidized polyisoprene IPN was created using TPO and TAS through the following procedure. A first intense irradiation at $365 \mathrm{~nm}$ or $>350 \mathrm{~nm}$ (filtered light) using TPO (TAS does not absorb in that case) creates a semi-IPN where the acrylate network (almost 95\% conversion within $5 \mathrm{~s}$; lamp intensity: $30 \mathrm{~mW} / \mathrm{cm}^{2}$ ) is embedded in the epoxidized polyisoprene. A second irradiation at $\lambda>250 \mathrm{~nm}$ (unfiltered UV light; TAS and the remaining TPO are excited) transforms the semi-IPN into a true IPN $(\sim 100 \%$ and $\sim 80 \%$ conversion for the acrylate and the epoxide, respectively after $5 \mathrm{~s}$ exposure to light) thanks to the cationic polymerization through the epoxy groups. Other examples can be found, e.g., in [52,61].

\subsection{UV-Thermal Dual Curing}

Combining a thermal treatment with a UV irradiation could be useful to cure coatings on three-dimensional objects where shadow areas can exist. Such a treatment was applied to acrylate/oxetane blends [27]: the polyacrylate network is formed at $80{ }^{\circ} \mathrm{C}$ ( $44 \%$ conversion); a subsequent 1 min of irradiation leads to a substantial oxetane conversion (about 74\%). The broad tan $\delta$ curve (from $60{ }^{\circ} \mathrm{C}$ up to $200{ }^{\circ} \mathrm{C}$ ) allows a broad damping effect of the final material. Other examples can be found in [105].

\subsection{Visible Light Curing of IPNs}

When using visible light sources (doped $\mathrm{Hg}$ lamps, Xe-Hg or Xe lamps), less UV lights are available and the intensities delivered at a function of the wavelength are often very different and lower. As a consequence, the $I_{\text {abs }}$ quantities absorbed by each PI can also be different which has a strong influence on the polymerization profiles. The same holds true with usual Hg lamps where less visible lights are available. Moreover, the use of (quasi) monochromatic visible sources is usually rather difficult, as in any case, the presence of UV lights is required to get a satisfactorily excitation of the available cationic photoinitiators. Moreover, the oxygen inhibition effect increases when the light intensities decrease. Therefore, up until recently, the free radical/cationic hybrid polymerization under visible lights was hardly carried out and restricted to the use of systems absorbing in the near UV/visible wavelength range (see e.g., [106]). 


\subsection{Recent Design of Dual Photoinitiating Systems Operating under Visible Lights}

To overcome these above mentioned limitations, one has to design a system that (i) contains one photosensitive compound (PI) and suitable additives, (ii) simultaneously generates radicals and cations (or radical cations), (iii) limits the oxygen inhibition effect and (iv) allows an excitation in the visible wavelength range.

We have recently designed such systems (see references below) that contain a reactive visible light absorbing PI, an iodonium salt $\mathrm{Ph}_{2} \mathrm{I}^{+}$and a silane $\mathrm{R}_{3} \mathrm{SiH}$ (or $N$-vinyl carbazole NVK) and work according to Scheme 4. The striking features are (i) the formation of the same cation $\mathrm{R}_{3} \mathrm{Si}^{+}$and the same radicals $\mathrm{R}_{3} \mathrm{Si} \bullet$, $\mathrm{Ph} \bullet$ whatever PI (i.e., whatever the excitation wavelength), (ii) the high efficiency of these produced cations and radicals for the initiation of CP and FRP, respectively, and (iii) the role of the silane in the consumption of oxygen, the scavenging of the peroxyls and the re-generation of new silyls. The phenyls and silyls as well as the silyliums are used to initiate separately but concomitantly the free radical polymerization FRP and the cationic polymerization CP process within a one-step sequence. The final coatings are tack-free.

Scheme 4. Reaction sequence in the presence of a silane.

$$
\begin{gathered}
\mathrm{PI} \rightarrow \mathrm{PI}^{*}(\mathrm{~h} v) \\
\mathrm{PI}^{*}+\mathrm{R}_{3} \mathrm{SiH} \rightarrow \mathrm{R}_{3} \mathrm{Si} \bullet+\mathrm{PI}-\mathrm{H} \bullet \\
\mathrm{Or} \mathrm{PI}^{*} \rightarrow \mathrm{R}_{1} \bullet+\mathrm{R}_{2} \bullet \text { and } \mathrm{R}_{1} \bullet+\mathrm{R}_{2} \bullet+\mathrm{R}_{3} \mathrm{SiH} \rightarrow \mathrm{R}_{3} \mathrm{Si} \bullet+\mathrm{R}_{1} \mathrm{H}+\mathrm{R}_{2} \mathrm{H} \\
\mathrm{R}_{3} \mathrm{Si} \bullet+\mathrm{O}_{2} \rightarrow \mathrm{R}_{3} \mathrm{SiOO} \bullet \\
\text { Medium }+ \text { oxygen } \rightarrow-\mathrm{OO} \bullet \\
-\mathrm{OO} \bullet+\mathrm{R}_{3} \mathrm{SiH} \rightarrow-\mathrm{OOH}+\mathrm{R}_{3} \mathrm{Si} \bullet \\
\mathrm{R}_{3} \mathrm{Si} \bullet+\mathrm{Ph}_{2} \mathrm{I}^{+} \rightarrow \mathrm{R}_{3} \mathrm{Si}^{+}+\mathrm{PhI}+\mathrm{Ph} \bullet
\end{gathered}
$$

Such useful PIs in these novel dual photoinitiating systems are derived from dye structures and include e.g., diketopyrrolopyrrole-thiophene derivatives [107], mono and polyfunctional thiophene derivatives [108], indanedione skeleton [109], naphthalene scaffold [110], naphthalimide and naphthalic anhydride derivatives [111], anthraquinone derivatives [112], chalcone derivatives [113], push-pull malonate and malonitrile based compounds [114], naphthalimide based methacrylated derivatives [115], $\alpha$-silicon polyoxomolybdate [116], acridinediones [117], difunctional acridinediones [118], Keggin-type polyoxometalate ion [119], push-pull structured indandiones [120], dimethyldihydropyrene [121], chromone based compounds [122], perylene bis-dicarboximides [123], pyrene derivatives [124], zinc complexes [125], pyridinium salts [126], pyrromethenes [127], trifunctional triazines [128], cyclometallated Pt(II) complexes [129], polyaromatic structures [130], and phenanthroline ligand containing Ru complex [131].

These systems are really versatile and have allowed the manufacture of IPNs under air at any wavelength (blue to red) depending only on the dye. The high reactivity of the photoinitiating systems is exemplified by the fact that low viscosity formulations where oxygen inhibition is much more important can be used (e.g., acrylate (TMPTA)/epoxide (EPOX), acrylate (TMPTA)/divinylether 
(DVE), thiol (trimethylolpropane tris (3-mercaptopropionate) TMSH)/divinylether (DVE)). For example, the manufacture of IPN materials can be carried out under exposure to a large variety of wavelengths delivered by a $\mathrm{Hg}-\mathrm{Xe}$ lamp (intensity $40 \mathrm{~mW} / \mathrm{cm}^{-2}$ ) $[116,119,128,130]$ or laser diodes (intensity $\sim 80 \mathrm{~mW} / \mathrm{cm}^{-2}$ ) at 385-405 nm [110], $457 \mathrm{~nm}$ [108,111,113-115,122,124], $473 \mathrm{~nm}$ [127], $473 \mathrm{~nm}$ (and likely 532, $635 \mathrm{~nm}$ ) [120], $532 \mathrm{~nm}$ [107,123], $635 \mathrm{~nm}$ [112], from 473 up to $635 \mathrm{~nm}$ [121]. This was achieved under air (for EPOX/TMPTA blends) or in laminate (for EPOX/DVE blends as seen, e.g., in $[124,125,127,128])$.

The attained performance can be exemplified here by the striking recent results obtained in the photopolymerization of a TMPTA/EPOX blend upon a blue to red light irradiation (Figure 1). For example, 2,7-di-tert-butyldimethyldihydropyrene (DHP) behaves as a panchromatic PI exhibiting good light absorption properties in the 400-700 nm range (Figure 1A) [121]. The synthesis of IPNs was easily carried out using DHP/DPI/NVK as PIS. Representative polymerization profiles of TMPTA/EPOX upon a red light are displayed in Figure 1B.

Figure 1. (A) UV-visible ground state spectrum of DHP in acetonitrile. (B) Photopolymerization profiles of a TMPTA/EPOX blend $(50 \% / 50 \%)$ under air using the DHP/DPI/NVK system $(1 \% / 2 \% / 3 \% w / w / w)$ upon a laser diode exposure at $635 \mathrm{~nm}$ (the conversions for double bond (for TMPTA) and epoxy (for EPOX) were followed by FTIR spectroscopy as presented in [121].

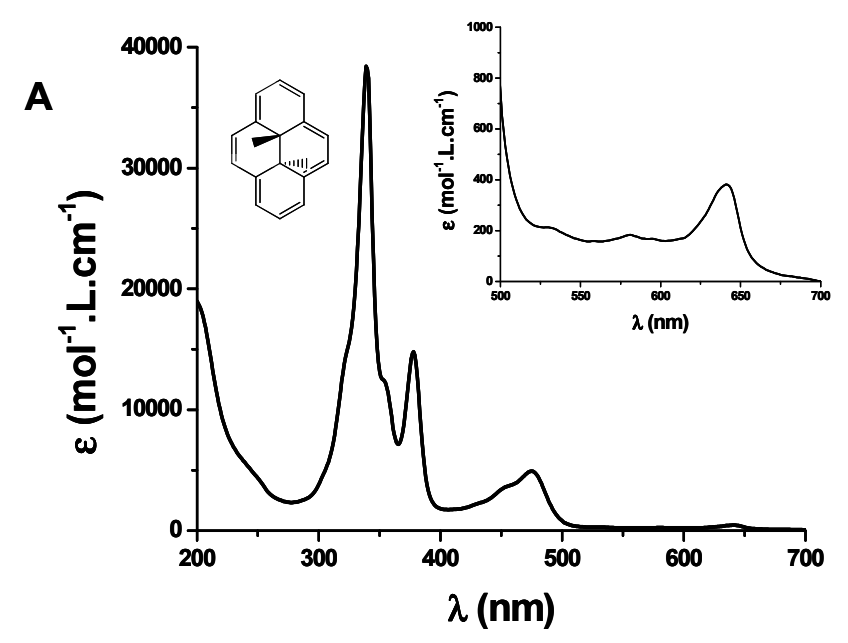

B

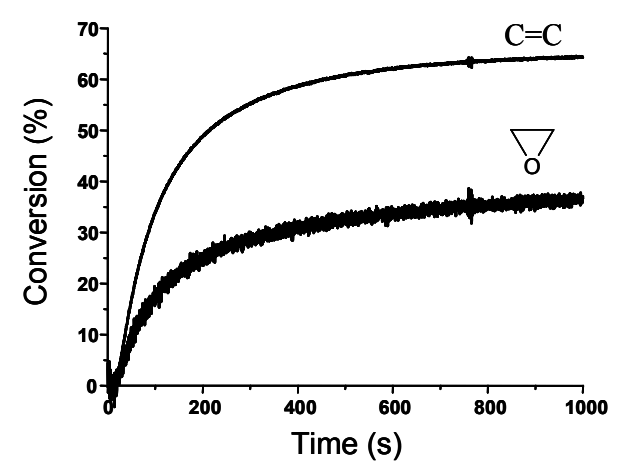

Thanks to the numerous original PIs recently designed [107-131], such IPN synthesis can be performed today with any selected irradiation devices: LEDs, laser diodes, laser beams, continuous 
lamps (halogen lamp, Xe, Xe-Hg lamps, etc.). The novel commercial and industrially used LED arrangements (with high intensities in the visible) can obviously operate and, of course, more viscous films should also easily be photopolymerized (as the oxygen inhibition is less detrimental).

As expected, novel surface and bulk properties are obtained, e.g., in epoxide/acrylate IPNs compared to those of the bulk polyether or polyacrylate. For example (see in [130]; $\mathrm{Hg}-\mathrm{Xe}$ lamp exposure), the contact angle on the surface of the EPOX/TMPTA $(50 \% / 50 \%)$ IPN film (water/polymer) is $62^{\circ}$ which can be compared to those of neat TMPTA $\left(49^{\circ}\right)$ and neat EPOX $\left(67^{\circ}\right)$ : both the polyether and polyacrylate networks are thus present at the surface. DMA analysis leads to one $T_{\mathrm{g}}$ value $\left(148{ }^{\circ} \mathrm{C}\right)$ suggesting that a phase separation is avoided (or at least limited) and supporting a good compatibility between the two chemical networks.

Attempts have been made to design one-component PIs that are able to generate both radicals and cationic species. This way is, however, rather hard. A newly synthesized iodonium polyoxomolybdate $\left[\left(\mathrm{SiMo}_{2} \mathrm{O}_{40}\right)^{4-}\right]\left(\mathrm{Ph}_{2} \mathrm{I}^{+}\right)_{4}$ plays this role for the TMPTA/EPOX blend polymerization upon a Xe-Hg lamp exposure. Initiating phenyls $\mathrm{Ph} \bullet$ and cations $\mathrm{M}^{+}$are formed (Scheme 5; $\mathrm{MH}$ being the cationic monomer). As before, excellent monomer conversions are obtained: $67 \%$ for EPOX and $78 \%$ for TMPTA under air (1000 s of UV light irradiation; tack free coatings). This way might be of interest as it avoids the introduction of several compounds (e.g., the silane or the iodonium salt in the above described three-component PISs) but the drawbacks are the design of suitable cationic moieties for a nice tuning of the absorption and the requirement of more or less complicated synthetic procedures.

Scheme 5. Chemical mechanisms involved in an iodonium polyoxomolybdate.

$$
\begin{gathered}
{\left[\left(\mathrm{SiMo}_{2} \mathrm{O}_{40}\right)^{4-}\right]\left(\mathrm{Ph}_{2} \mathrm{I}^{+}\right)_{4} \rightarrow *\left[\left(\mathrm{SiMo}_{2} \mathrm{O}_{40}\right)^{4-}\right]\left(\mathrm{Ph}_{2} \mathrm{I}^{+}\right)_{4}(\mathrm{~h} v)} \\
\text { and } *\left[\left(\mathrm{SiMo}_{2} \mathrm{O}_{40}\right)^{4-}\right]\left(\mathrm{Ph}_{2} \mathrm{I}^{+}\right)_{4} \rightarrow\left[\left(\mathrm{SiMo}_{2} \mathrm{O}_{40}\right)^{3-}\right]\left(\mathrm{Ph}_{2} \mathrm{I}^{+}\right)_{3}+\mathrm{Ph} \bullet+\mathrm{Ph}-\mathrm{I} \\
\mathrm{Ph} \bullet+\mathrm{MH} \rightarrow \mathrm{PhH}+\mathrm{M} \bullet \text { and } \mathrm{M} \bullet+\mathrm{Ph}_{2} \mathrm{I}^{+} \rightarrow \mathrm{M}^{+}+\mathrm{Ph} \bullet+\mathrm{PhI}
\end{gathered}
$$

\subsection{Photocuring of IPNs under Soft Conditions}

The PI/iodonium salt/silane (or NVK) systems can also work for the simultaneous photocuring of IPNs under soft conditions (under air, under visible lights, under low light intensity). For example, various low viscosity blends of e.g., TMPTA/EPOX, TMPTA/DVE, TMSH/DVE can be polymerized under exposure to low intensity lights (intensity $<8 \mathrm{~mW} / \mathrm{cm}^{-2}$ ) emitted by household devices such as a halogen lamp [117,118,125,126,129], a fluorescent bulb (peaks at 430, $550 \mathrm{~nm}$ ) [131], a blue led at $462 \mathrm{~nm}[109,132]$ and even sunlight (intensity $\sim 2 \mathrm{~mW} / \mathrm{cm}^{-2}$ ).

Three representative examples are the following. When the polyaromatic chromophore depicted in Figure 2a is used in combination with DPI and a silane (or NVK) under a halogen lamp, an efficient simultaneous TMPTA/EPOX polymerization with final conversions of $55 \%$ (EPOX) and $75 \%$ (TMPTA) is readily achieved [130].

Different PIs (Anth, Napht and Pent) exhibit a suitable visible light absorption (Figure 3 [132]); upon very soft blue (for Anth), green (for Napht) and yellow and red (for Pent) LED bulb exposures $\left(\sim 10 \mathrm{~mW} / \mathrm{cm}^{2}\right)$ good polymerization processes can be observed for EPOX/TMPTA blends using these $\mathrm{PIs} / \mathrm{DPI} /$ silane photoinitiating systems. 
Figure 2. Structure of (a) $T_{-} 1$ and (b) conversion profiles for the epoxy and acrylate double bond functions for an EPOX/TMPTA blend $(50 \% / 50 \% \mathrm{w} / \mathrm{w})$ upon halogen lamp; irradiation under air in the presence of T_1/(TMS) ${ }_{3} \mathrm{Si}-\mathrm{H} / \mathrm{Ph}_{2} \mathrm{I}^{+}(0.2 \% / 3 \% / 2 \% w / w / w)$.

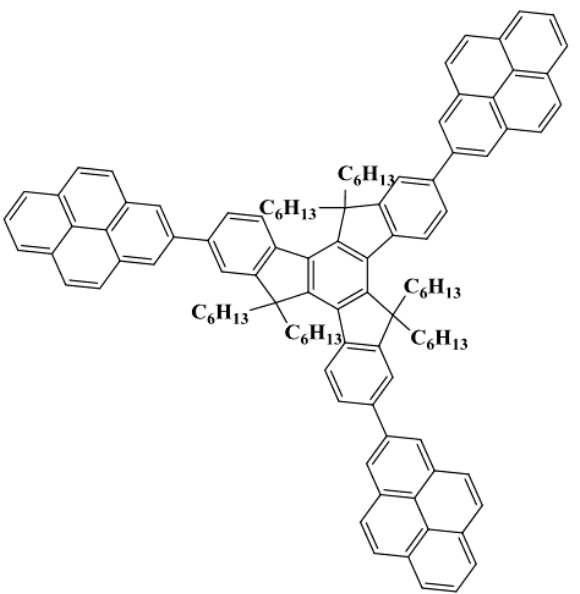

(a)

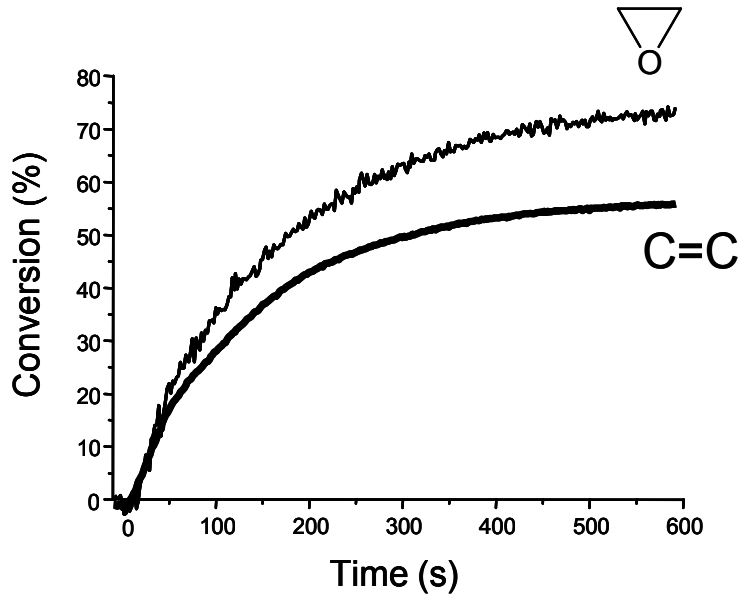

(b)

Figure 3. Visible light absorption spectra (O.D. for Optical Density) of different photoinitiators (Anth, Napht and Pent) in acetonitrile.
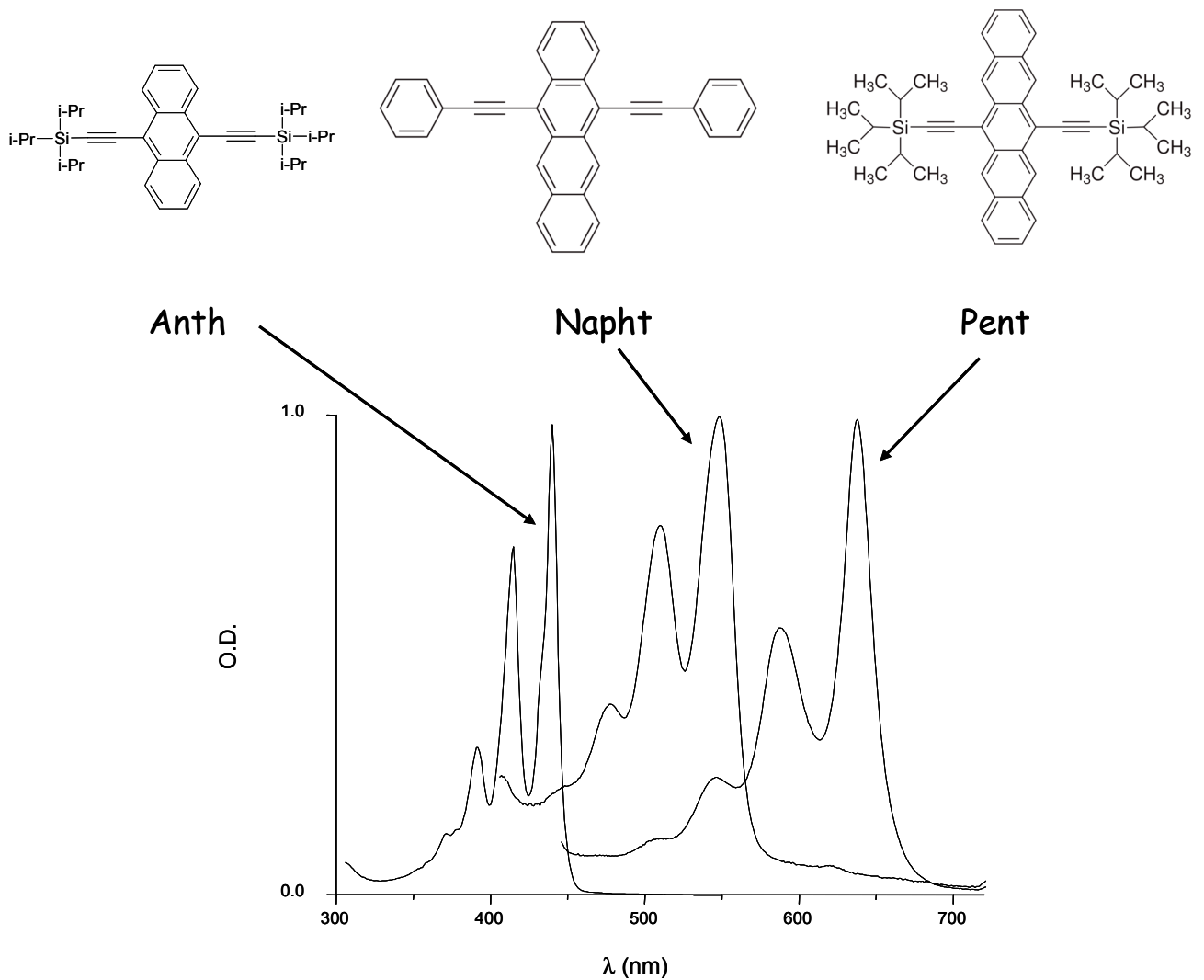

Similarly, under a polychromatic irradiation (halogen lamp; intensity $\sim 12 \mathrm{~mW} / \mathrm{cm}^{2}$ ), a truxene acridinedione (Tr_AD1)/DPI recently proposed PIS [120] is also very efficient (Figure 4).

These results confirm that quite high EPOX and TMPTA conversions in the formed IPNs can be obtained even under soft experimental conditions. Moreover, a noticeable difference is noted when the photopolymerization is conducted under air or in laminate. For example, when using a benzophenone 
derivative/DPI/NVK system upon exposure to a household blue led at $462 \mathrm{~nm}$ [133], conversions of 63\% (EPOX) and 56\% (TMPTA) under air and 43\% (EPOX) and 78\% (TMPTA) in laminate are reached. This behavior is ascribed to the fact that the EPOX conversion is lower in laminate because the reduced oxygen inhibition effect and the predominant consumption of radicals in the FRP of TMPTA (rather than by the CP/FRPCP of EPOX).

The polymerization of TMPTA/DVE blends $(50 \% / 50 \%)$ in laminate leads to conversions of, e.g., 85\% DVE and 55\% TMPTA (see in [127]; $457 \mathrm{~nm}$ laser diode or halogen lamp); no IPN can be formed under air as DVE alone is unable to polymerize in such selected experimental conditions. The different TMPTA and DVE conversions are accounted for by the formation of several polymers: a vinylether homopolymer through the $\mathrm{CP}$ of vinylether units (i), an acrylate/vinylether copolymer (ii) (where the initiating radicals add both to the acrylate and the vinylether double bond) and a copolymer structure (iii) resulting from the difunctional character of DVE that allows a combination of the (i) and (ii) processes. In DSC (differential scanning calorimeter) experiments, two $T_{\mathrm{g}}$ values are measured. The low $T_{\mathrm{g}}\left(-11^{\circ} \mathrm{C}\right)$ is mainly ascribed to the homopolymer (i) as the $T_{\mathrm{g}}$ of polymerized neat DVE is $\left.<30{ }^{\circ} \mathrm{C}\right)$; it ensures a high flexibility of the final material even at room temperature. The high $T_{\mathrm{g}}\left(11{ }^{\circ} \mathrm{C}\right)$ is attributed to the acrylate/vinylether network (ii, iii) and ensures the high hardness of the IPN. Other PISs can lead to similar DVE and TMPTA conversions (80\%) [125].

Figure 4. Conversions of the acrylate double bond and the epoxide during the photopolymerization of a TMPTA/EPOX blend (50\%/50\%) in laminate upon a halogen lamp irradiation in the presence of Tr_AD1/DPI initiating system $(0.5 \% / 3 \% \mathrm{w} / \mathrm{w})$.
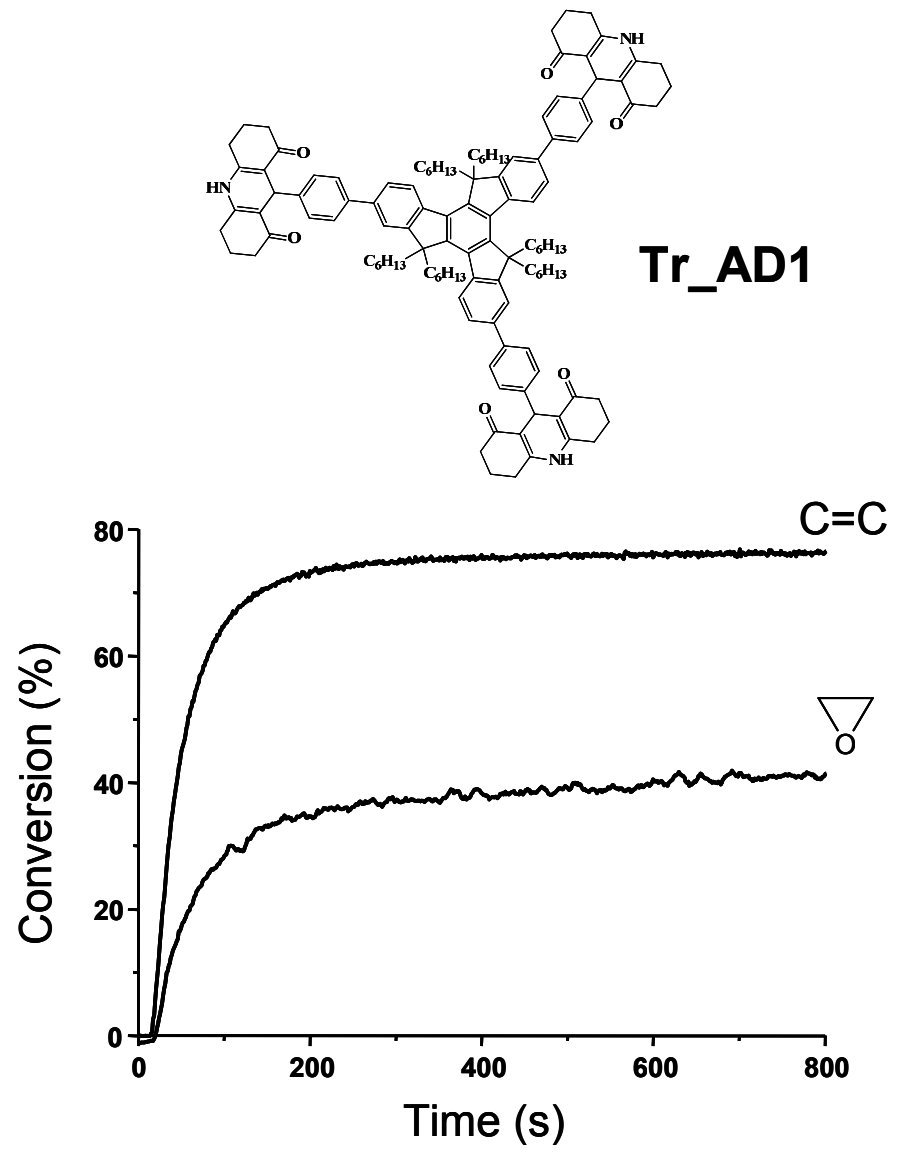
The hybrid cure of EPOX/NVK blends and thiol (TMSH)/acrylate (TMPTA) media is also feasible using three-component PI/silane/iodonium salt PISs [112,113].

The reactivity/efficiency difference of these novel PISs compared with previously used PIs, two examples can be highlighted by the following results. Twenty years ago, semi IPNs based on an acrylate monomers dispersed in a solid matrix (such as polymethyl methacrylate or in a styrene-butadiene rubber) [134] and IPNs formed from an acrylate and an epoxidized natural rubber [135] have been synthesized under sunlight under air within minutes using conventional PIs (such as TPO): this was possible owing to the high matrix viscosity and, as a consequence, the reduction of the oxygen inhibition. In contrary, other low viscosity radical/cationic matrices cannot be photopolymerized except when using a two-step procedure where the first irradiation of the epoxide produces a viscous matrix in which the acrylate can further polymerize [134,135]. Nowadays, however, even low viscosity TMPTA, EPOX or TMPTA/EPOX blends that are easily polymerized under very low intensity artificial sources under air in the presence of our newly developed PISs (see above) should also be polymerized under sunlight. This has been confirmed with the DHP/DPI/NVK system presented above for the manufacture of an acrylate/epoxy blend. Interesting reviews about possibilities and interests of IPNs can also be found in [136-140].

\section{Conclusions}

This paper has shown what has been done up to now in the manufacture of IPNs using a photochemical technology. The versatility of the light induced processes for the initiation of radical and cationic polymerizations reactions is certainly a decisive factor in the choice or the possibilities of applications. A significant progress in the design of photoinitiating systems allowing the simultaneous formation of both networks under low intensity visible lights (and under air with acrylate/epoxide) is clearly observed, but improvements are still expected (for example, in the control of the monomer conversions, the access of other functionalities (e.g., caprolactone, lactide, etc.). A forthcoming challenge might be the proposal of photoinitiating systems being able to sequentially operate in the same experimental conditions. This could still be useful in further fine tuning the final properties (mechanical properties, chemical properties, etc.). Among others, the recent works carried out in low viscosity media under soft irradiation conditions are promising for a lot of applications in various areas as they should likely be transposed to other photopolymerizable monomer blends, thereby opening up new opportunities.

\section{Conflicts of Interest}

The authors declare no conflict of interest.

\section{References}

1. Sperling, L.H. Interpenetrating Polymer Networks and Related Materials; Plenum Press: New York, NY, USA, 1981.

2. Sperling, L.H. Interpenetrating polymer networks. In Encyclopedia of Polymer Science and Technology; Wiley: New York, NY, USA, 2004. 
3. Selvaraj, M. Interpenetrating polymer networks, high performance. In Wiley Encyclopedia of Composites; Wiley: New York, NY, USA, 2012.

4. Stepto, R.F.T. Polymer Networks: Principles of Their Formation, Structure and Properties; Kluwer Academic Publishers: Dordrecht, The Netherlands, 1997; Chapter 6.

5. Sperling, L.H. Interpenetrating polymer networks. In Advances in Chemistry; Klepner, D., Utracki, L.A., Eds.; American Chemical Society (ACS): Washington, DC, USA, 1994.

6. Allen, N.S. Photochemistry and Photophysics of Polymer Materials; Wiley: New York, NY, USA, 2010.

7. Belfied, K.D.; Crivello, J.V. Photoinitiated. Polymerization; American Chemical Society (ACS): Washington, DC, USA, 2003.

8. Davidson, S. Exploring the science. In Technology and Application of UV and EB Curing; Sita Technology Ltd.: London, UK, 1999.

9. Neckers, D.C.; Jager, W. UV and EB at the Millenium; Sita Technology: London, UK, 1999.

10. Fouassier, J.P. Photoinitiation, Photopolymerization, and Photocuring: Fundamentals and Applications; Hanser: Münich, Germany, 1995.

11. Scranton, A.B.; Bowman, C.N.; Peiffer, R.W. Photopolymerization: Fundamentals and applications. In American Chemical Society Symposium Series; American Chemical Society (ACS): Washington, DC, USA, 1997.

12. Fouassier, J.P.; Rabek, J.F. Lasers in Polymer Science and Technology: Applications; CRC Press: Boca Raton, FL, USA, 1990.

13. Pappas, S.P. UV-Curing: Science and Technology; Plenum Press: New York, NY, USA, 1992.

14. Fouassier, J.P.; Rabek, J.F. Radiation Curing in Polymer Science and Technology; Chapman \& Hall: London, UK, 1993.

15. Fouassier, J.P.; Allonas, X. Basics and Applications of Photopolymerization Reactions; Research Signpost: Trivandrum, India, 2010.

16. Fouassier, J.P. Photochemistry and UV Curing: New Trends; Research Signpost: Trivandrum, India, 2006.

17. Mishra, M.K.; Yagci, Y. Handbook of Vinyl Polymers; CRC Press: Boca Raton, FL, USA, 2009.

18. Sangermano, M.; Carbonaro, W.; Bongiovanni, R.; Thomas, R.; Kausch, C.M. Interpenetrating polymer networks of hydrocarbon. Macromol. Mater. Eng. 2010, 295, 469-475.

19. Decker, C. Photoinitiated cross-linking polymerization of monomer blends. In Photoinitiated Polymerization; Belfied, K.D., Crivello, J.V., Eds.; American Chemical Society (ACS): Washington, DC, USA, 2003; Chapter 8, pp. 92-104.

20. Decker, C.; Nguyen Thi Viet, T.; Decker, D.; Weber-Koehl, E. UV-radiation curing of acrylate/epoxide systems. Polymer 2001, 42, 5531-5541.

21. Decker, C.; Le Xuan, H.; Nguyen Thi Viet, T. Photocrosslinking of functionalized rubber III. Polymerization of multifunctional monomers in epoxidized liquid natural rubber. J. Polym. Sci. A Polym. Chem. 1996, 34, 1771-1788.

22. Lecamp, L.; Pavillon, C.; Lebaudy, P.; Bunel, C. Influence of temperature and nature of photoinitiator on the formation kinetics of an interpenetrating network photocured from an epoxide/methacrylate system. Eur. Polym. J. 2005, 41, 169-175. 
23. Lin, Y.; Stansbury, J.W. Kinetics studies of hybrid structure formation by controlled photopolymerization. Polymer 2003, 44, 4781-4788.

24. Choe, J.-D.; Hong, J.W. UV-initiated free radical and cationic photopolymerizations of acrylate/epoxide and acrylate/vinyl ether hybrid systems with and without photosensitizer. J. Appl. Polym. Sci. 2004, 93, 1473-1483.

25. Rajaraman, C.; Mowers, W.A.; Crivello, J.V. Novel hybrid monomers bearing cycloaliphatic epoxy and 1-propenyl ether groups. Macromolecules 1999, 32, 36-41.

26. Sangermano, M.; Malucelli, G.; Bongiovanni, R.; Priola, A. Photopolymerization of oxetanes based systems. Eur. Polym. J. 2004, 40, 353-358.

27. Sangermano, M.; Malucelli, G.; Priola, A.; Manea, M. Recent advances in elastomeric nanocomposites. Prog. Org. Coat. 2006, 55, 225-230.

28. Sangermano, M.; Carbonaro, W.; Malucelli, G.; Priola, A. Polymer networks: Preparation and characterization. Macromol. Mater. Eng. 2008, 293, 515-520.

29. Decker, C. Kinetic study and new applications of UV radiation curing. Macromol. Rapid Commun. 2002, 23, 1063-1093.

30. Crivello, J.V.; Narayan, R.; Sternstein, S.S. Fabrication and mechanical characterization of glass fiber reinforced UV-cured composites from epoxidized vegetable oils. J. Appl. Polym. Sci. 1997, 64, 2073-2087.

31. Thames, S.F.; Yu, H. Cationic UV-cured coatings of epoxide-containing. Surf. Coat. Technol. 1999, 115, 208-214.

32. Decker, C.; Bianchi, C.; Decker, D.; Morel, F. Radiation curing: Coatings and printing inks. Prog. Org. Coat. 2001, 42, 253-266.

33. Kim, Y.M.; Kostanski, L.K.; Mac Gregor, J.F. Carboxylate and tri(ethylene glycol) methyl vinyl ether. Polymer 2003, 44, 5103-5109.

34. Rajaraman, S.K.; Mowers, W.A.; Crivello, J.V. Interaction of epoxy and vinyl ethers during photoinitiated cationic polymerization. J. Polym. Sci. A Polym. Chem. 1999, 37, 4007-4018.

35. Tehfe, M.A.; Dumur, F.; Vilas, N.; Graff, B.; Mayer, C.R.; Fouassier, J.P.; Gigmes, D.; Lalevée, J. A multicolor photoinitiator for cationic polymerization and interpenetrated polymer network synthesis: 2,7-di-tert-butyldimethyldihydropyrene. Macromol. Rapid Commun. 2013, 34, 1104-1109.

36. Nakanishi, H.; Satoh, M.; Norisuye, T.; Tran-Cong-Miyata, Q. Phase separation of interpenetrating polymer networks synthesized by using an autocatalytic reaction. Macromolecules 2006, 39, 9456-9466.

37. Vancaeyzeele, C.; Fichet, O.; Laskar, J.; Boileau, S.; Teyssié, D. Polyisobutene/polystyrene interpenetrating polymer networks: Effects of network formation order and composition on the IPN architecture. Polymer 2006, 47, 2046-2060.

38. Lu, C.-H.; Su, Y.-C.; Wang, C.-F.; Huang, C.-F.; Sheen, Y.-F.; Chang, F.-C. Thermal properties and surface energy characteristics of interpenetrating polyacrylate and polybenzoxazine networks. Polymer 2008, 49, 4852-4860.

39. Boudraa, K.; Bouchaour, T.; Maschke, U. Swelling of acrylic interpenetrating polymer networks in liquid crystals. Macromol. Symposia 2008, 273, 33-37. 
40. Boudraa, K.; Bouchaour, T.; Maschke, U. Equilibrium phase diagrams of interpenetrating polymer networks and liquid crystals. Macromol. Symposia 2011, 303, 95-99.

41. Wang, J.; Sun, F.; Li, X. Preparation and antidehydration of interpenetrating polymer network hydrogels based on 2-hydroxyethyl methacrylate and $N$-vinyl-2-pyrrolidone. J. Appl. Polym. Sci. 2010, 117, 1851-1858.

42. Karabanova, L.V.; Boiteux, G.; Seytre, G.; Stevenson, I.; Lloyd, A.W.; Mikhalovsky, S.V.; Helias, M.; Sergeeva, L.M.; Lutsyk, E.D.; Svyatyna, A. Phase separation in the polyurethane/poly(2-hydroxyethyl methacrylate) semi-interpenetrating polymer networks synthesized by different ways. Polym. Eng. Sci. 2008, 48, 588-597.

43. Pescosolido, L.; Vermonden, T.; Malda, J.; Censi, R.; Dhert, W.J.A.; Alhaique, F.; Hennink, W.E.; Matricardi, P. In situ forming IPN hydrogels of calcium alginate and dextran-HEMA for biomedical applications. Acta Biomater. 2011, 7, 1627-1633.

44. Sangermano, M.; Cook, W.D.; Papagna, S.; Grassini, S. Curing kinetics and morphology of IPNs from a flexible dimethacrylate and a rigid epoxy via sequential photo and thermal polymerization. Eur. Polym. J. 2012, 48, 1796-1804.

45. Sangermano, M.; Razza, N.; Crivello, J.V. Cationic UV-curing: Technology and applications. Macromol. Mater. Eng. 2014, 41, 775-793.

46. Naga, N.; Kihara, Y.; Miyanaga, T.; Furukawa, H. A photo hydrosilylation reaction. Macromolecules 2009, 42, 3454-3462.

47. Moussa, K.; Decker, C. Semi-interpenetrating polymer networks synthesis. J. Polym. Sci. A Polym. Chem. 1993, 31, 2633-2642.

48. Pescosolido, L.; Schuurman, W.; Malda, J.; Matricardi, P.; Alhaique, F.; Coviello, P.; van Weeren, R.; Dhert, W.J.A.; Hennink, W.E.; Vermonden, T. Hyaluronic acid and dextran-based semi-IPN hydrogels as biomaterials for bioprinting. Biomacromolecules 2011, 12 , 1831-1838.

49. Decker, C.; Decker, D.; Nguyen Thi Viet, T.; Le Xuan, H. Photoinitiated cationic polymerisation of multifunctional systems. Macromol. Symposia 1996, 102, 63-71.

50. Yang, T.; Malkoch, M.; Hult, A. Sequential interpenetrating poly(ethylene glycol) hydrogels prepared by UV-initiated thiol-ene coupling chemistry. J. Polym. Sci. A Polym. Chem. 2013, 51, 363-371.

51. Guymon, J.; Clapper, D.; Guymon, C.A. Compatibilization of immiscible polymer networks through photopolymerization in a lyotropic liquid crystal. Adv. Mater. 2006, 18, 1575-1580.

52. Ortiz, R.A.; Urbina, B.A.P.; Valdez, L.V.C.; Duarte, L.B.; Santos, R.G.; Valdez, A.I.G.; Santos, R.G.; Valdez, A.E.G.; Soucek, M.D. Effect of introducing a cationic system into a thiol-ene photopolymerizable formulation. J. Polym. Sci. A Polym. Chem. 2007, 45, 4829-4843.

53. Wei, H.; Li, Q.; Ojelade, M.; Madbouly, S.; Otaigbe, J.U.; Hoyle, C.E. Thiol-ene free-radical and vinyl ether cationic hybrid photopolymerization. Macromolecules 2007, 40, 8788-8793.

54. He, Y.; Xiao, M.; Wu, F.; Nie, J. Photopolymerization kinetics of cycloaliphatic epoxide-acrylate hybrid monomer. Polym. Int. 2007, 56, 1292-1297.

55. Xiao, M.; Shi, S.; Nie, J.; He, Y. Photopolymerization kinetics study of epoxide/acrylate hybrid oligomer. PMSE Prepr. 2006, 94, 408-409. 
56. Crivello, J.V. Synergistic effects in hybrid free radical/cationic photopolymerizations. J. Polym. Sci. A Polym. Chem. 2007, 45, 3759-3769.

57. Crivello, J.V. Hybrid free radical/cationic frontal photopolymerizations. J. Polym. A Polym. Chem. 2007, 45, 4331-4340.

58. Cai, Y.; Jessop, J.L.P. Decreased oxygen inhibition in photopolymerized acrylate/epoxide hybrid polymer coatings as demonstrated by Raman spectroscopy. Polymer 2006, 47, 6560-6566.

59. Crivello, J.V. Redox initiated cationic polymerization: The unique behavior of alkyl glycidyl ethers. J. Polym. Sci. A Polym. Chem. 2011, 49, 2147-2154.

60. Jian, Y.; He, Y.; Sun, Y.; Yang, H.; Yang, W.; Nie, J. Thiol-epoxy/thiol-acrylate hybrid materials synthesized by photopolymerization. J. Mater. Chem. C 2013, 1, 4481-4489.

61. De Ruiter, B.; El Ghayoury, A.; Hofmeir, H.; Schubert, U.S.; Manea, M. Two-step curing processes for coating application. Prog. Org. Coat. 2006, 55, 154-159.

62. Bourcier, S.; Vancaeyzeele, C.; Vidal, F.; Fichet, O. Microemulsion as the template for synthesis of interpenetrating polymer networks with predefined structure. Polymer 2013, 54, 4436-4445.

63. Cook, W.D. Photopolymerization kinetics of oligo(ethylene oxide) and oligo(methylene) oxide dimethacrylates. J. Polym. Sci. A Polym. Chem. 1993, 31, 1053-1067.

64. Chen, F.; Cook, W.D. Hybrid UV-cured organic-inorganic IPNs. Eur. Polym. J. 2008, 44, 1796-1813.

65. De Brito, M.; Allonas, X.; Croutxé-Barghorn, C.; Palmieri, M.; Dietlin, C.; Agarwal, S.; Lellinger, D.; Alig. I. Kinetic study of photoinduced quasi-simultaneous interpenetrating polymer networks. Prog. Org. Coat. 2012, 73, 186-193.

66. Nowers, J.R.; Costanzo, J.A.; Narasimhan, B. Structure-property relationships in acrylate/epoxy interpenetrating polymer networks: Effects of the reaction sequence and composition. J. Appl. Polym. Sci. 2007, 104, 891-901.

67. Lee, S.; Jeong, Y.C.; Heo, Y.; Kim, S., II; Choi, Y.-S.; Park, J.-K. Holographic photopolymers of organic/inorganic hybrid interpenetrating networks for reduced volume shrinkage. J. Mater. Chem. 2009, 19, 1105-1114.

68. Carioscia, J.A.; Stansbury, J.W.; Bowman, C.N. Evaluation and control of thiol-ene/thiol-epoxy hybrid networks. Polymer 2007, 48, 1526-1532.

69. Wang, J.; Liu, F. Synthesis and application of ion-imprinted interpenetrating polymer network gel for selective solid phase extraction of $\mathrm{Cd}^{2+}$. Chem. Eng. J. 2014, 242, 117-126.

70. Wang, J.; Liu, F. UV-radiation curing of simultaneous interpenetrating polymer network hydrogels for enhanced heavy metal ion removal. Mater. Sci. Eng. B 2012, 177, 1633-1640.

71. Nakanishi, H.; Namikawa, N.; Norisuye, T.; Tran-Cong-Miyata, Q. Interpenetrating polymer networks with spatially graded morphology controllable by UV-radiation curing. Macromol. Symposia 2006, 242, 157-164.

72. Daniele, M.D.; Adams, A.A.; Naciri, J.; North, S.H.; Ligler, F.S. Interpenetrating networks based on gelatin methacrylamide and PEG formed using concurrent thiol click photopolymerization for hydrogel tissue engineering scaffolds. Biomaterials 2014, 35, 1845-1856.

73. Kundu, J.; Poole-Warren, L.A.; Martens, P.; Kundu, S.C. Silk fibroin/poly(vinyl alcohol) photocrosslinked hydrogels for delivery of macromolecular drugs. Acta Biomater. 2012, 8, $1720-1729$. 
74. Xiao, W.; He, J.; Nichol, J.W.; Wang, L.; Hutson, C.B.; Wang, B.; Du, Y.; Fan, H.; Khademhosseini, A. Synthesis and characterization of photocrosslinkable gelatin and silk fibroin interpenetrating polymer network hydrogels. Acta Biomater. 2011, 7, 2384-2393.

75. Matricardi, P.; di Meo, C.; Coviello, T.; Hennink, W.E.; Alhaique, F. Interpenetrating polymer networks polysaccharide hydrogels for drug delivery and tissue engineering. Adv. Drug Deliver. Rev. 2013, 65, 1172-1187.

76. Rennerfeldt, D.A.; Renth, A.N.; Talata, Z.; Gehrke, S.H.; Detamore, M.S. Tuning mechanical performance of poly(ethylene glycol) and agarose interpenetrating network hydrogels for cartilage tissue engineering. Biomaterials 2013, 34, 8241-8257.

77. Liu, Y.; Chan-Park, M.B. Hydrogel based on interpenetrating polymer networks of dextran and gelatin for vascular tissue engineering. Biomaterials 2009, 30, 196-207.

78. Myung, D.; Koh, W.; Ko, J.; Hu, Y.; Carrasco, M.; Noolandi, J.; Ta, C.N.; Frank, C.W. Biomimetic strain hardening in interpenetrating polymer network hydrogels. Polymer 2007, 48, 5376-5387.

79. Lee, Y.; Kim, D.N.; Choi, D.; Lee, W.; Park, J.; Koh, W.G. Preparation of interpenetrating polymer network composed of poly(ethylene glycol) and poly(acrylamide) hydrogels as a support of enzyme immobilization. Polym. Adv. Technol. 2008, 19, 852-858.

80. Bae, K.H.; Wang, L.-S.; Kurisawa, M. Injectable biodegradable IPN hydrogels: Progress and challenges. J. Mater. Chem. B 2013, 1, 5371-5388.

81. Liu, Y.-Y.; Lü, J.; Shao, Y.-H. Preparation And Characterization Of Poly( $N$-Isopropylacrylamide)Modified Poly(2-Hydroxyethyl Acrylate) Hydrogels By Interpenetrating Polymer Networks For Sustained Drug Release. Macromol. Biosci. 2006, 6, 452-458.

82. Zhao, S.-P.; Ma, D.; Zhang, L.-M. New semi-interpenetrating network hydrogels: Synthesis, characterization and properties. Macromol. Biosci. 2006, 6, 445-451.

83. Dragan, E.S. Design and applications of interpenetrating polymer network hydrogels. A review. Chem. Eng. J. 2014, 243, 572-590.

84. Cha, C.; Kim, S.R.; Jin, Y.-S.; Kong, H. Tuning structural durability of yeast-encapsulating alginate gel beads with interpenetrating networks for sustained bioethanol production. Biotechnol. Bioeng. 2012, 109, 63-73.

85. Elisseeff, J.; McIntosh, W.; Anseth, K.; Riley, S.; Ragan, P.; Langer, R. Photoencapsulation of chondrocytes in poly(ethylene oxide)-based semi-interpenetrating networks. J. Biomed. Mater. Res. 2000, 51, 164-171.

86. Liu, S.; Zhao, N.; Rudenja, S. Surface interpenetrating networks of poly(ethylene terephthalate) and polyamides for effective biocidal properties. Macromol. Chem. Phys. 2010, 211, 286-296.

87. Li, J.; Lin, F.; Li, L.; Li, J.; Liu, S. Surface engineering of poly(ethylene terephthalate) for durable hemocompatibility via a surface interpenetrating network technique. Macromol. Chem. Phys. 2012, 213, 2120-2129.

88. Zhang, S.; Feng, Y.; Zhang, L.; Sun, J.; Xu, X.; Xu, Y. Novel interpenetrating networks with shape-memory properties. J. Polym. Sci. A Polym. Chem. 2007, 45, 768-775.

89. Myung, D.; Farooqui, N.; Zheng, L.L.; Koh, W.; Gupta, S.; Bakri, A.; Noolandi, J.; Cochran, J.R.; Frank, C.W.; Ta, C.N. Bioactive interpenetrating polymer network hydrogels that support corneal epithelial wound healing. J. Biomed. Mater. Res. A 2009, 90A, 70-81. 
90. Akpalo, E.; Bidault, L.; Boissière, M.; Vancaeyzeele, C.; Fichet, O.; Larreta-Garde, V. Fibrin-polyethylene oxide interpenetrating polymer networks: New self-supported biomaterials combining the properties of both protein gel and synthetic polymer. Acta Biomater. 2011, 7 , 2418-2427.

91. Zheng, X.L.; Weng, J.-B.; Huang, Q.-M.; Hu, B.-H.; Qiao, T.; Deng, P. Fabrication of a stable poly(vinylpyrrolidone)/poly(urushiol) multilayer ultrathin film through layer-by-layer assembly and photo-induced polymerization. Colloids Surf. A Physicochem. Eng. Asp. 2009, 337, 15-20.

92. Karabanova, L.V.; Mikhalovsky, S.V.; Lloyd, A.W. Gradient semi-interpenetrating polymer networks based on polyurethane and poly(2-hydroxyethyl methacrylate) for biomedical applications. J. Mater. Chem. 2012, 22, 7919-7928.

93. Jain, S.H.; Murata, K.; Anazawa, T. Nanostructures developed from semi-interpenetrating polymer network structures. Macromol. Chem. Phys. 2003, 204, 893-902.

94. Forney, B.S.; Baguenard, C.; Guymon, C.A. Improved stimuli-response and mechanical properties of nanostructured poly( $N$-isopropylacrylamide- $c o$-dimethylsiloxane) hydrogels generated through photopolymerization in lyotropic liquid crystal templates. Soft Matter 2013, 9 , 7458-7467.

95. Lav, T.X.; Tran-Van, F.; Vidal, F.; Péralta, S.; Chevrot, C.; Teyssié, D.; Grazulevicius, J.V.; Getautis, V.; Derbal, H.; Nunzi, J.-M.; et al. Synthesis and characterization of $\mathrm{p}$ and $\mathrm{n}$ dopable interpenetrating polymer networks for organic photovoltaic devices. Thin Solid Films 2008, 516, 7223-7229.

96. Park, S.; Bearinger, J.P.; Lautenschlager, E.P.; Castner, D.G.; Healy, K.E. Surface modification of poly(ethylene terephthalate) angioplasty balloons with a hydrophilic poly(acrylamide-coethylene glycol) interpenetrating polymer network coatings. J. Biomed. Mater. Res. 2000, 53, 568-576.

97. Chan, B.K.; Wippich, C.C.; Wu, C.J.; Sivasankar, P.M.; Schmidt, G. Robust and semi-interpenetrating hydrogels from poly(ethylene glycol) and collagen for elastomeric tissue scaffolds. Macromol. Biosci. 2012, 12, 1490-1501.

98. Nakabayashi, N. Contribution of polymer chemistry to dentistry: Development of an impermeable interpenetrating polymer network to protect teeth from acid demineralization. Polym. Int. 2008, 57, 159-162.

99. Garoushi, S.; Vallittu, P.K.; Lassila, L.V.J. Short glass fiber reinforced restorative composite resin with semi-inter penetrating polymer network matrix. Dent. Mater. 2007, 23, 1356-1362.

100. Fouassier, J.P.; Lalevée, J. Photoinitiators for Polymer Synthesis-Scope, Reactivity, and Efficiency; Wiley-VCH: Weinheim, Germany, 2012.

101. Dietliker, K. A Compilation of Photoinitiators Commercially Available for UV Today; Sita Technology Ltd.: London, UK, 2002.

102. Crivello, J.V. Photoinitiators for Free Radical, Cationic and Anionic Photopolymerization, 2nd ed.; John Wiley \& Sons: Chichester, UK, 1998.

103. Green, W.A. Industrial Photoinitiators; CRC Press: Boca Raton, FL, USA, 2010.

104. Vabrik, R.; Czajlik, I.; Túry, G.; Rusznák, I.; Ille, A.; Víg, A.; Hult, A. Study of epoxy resin-acrylated polyurethane semi-interpenetrating polymer networks. J. Appl. Polym. Sci. 1998, 68, 111-119. 
105. Dean, K.; Cook, W.D. Effect of curing sequence on the photopolymerization and thermal curing kinetics of dimethacrylate/epoxy interpenetrating polymer networks. Macromolecules 2002, 35, $7942-7954$.

106. Podsiadły, R.; Podemska, K.; Szymczak, A.M. Novel visible photoinitiators systems for free-radical/cationic hybrid photopolymerization. Dyes Pigment. 2011, 91, 422-426.

107. Lalevee, J.; Dumur, F.; Gigmes, D.; Graff, B.; Xiao, P.; Fouassier, J.P.; Hong, W.; Li, Y. Green light sensitive diketopyrrolopyrrole derivatives used in versatile photoinitiating systems for photopolymerizations. Polym. Chem. 2014, 5, 2293-2300.

108. Xiao, P.; Dumur, F.; Thirion, D.; Fagour, S.; Vacher, A.; Sallenave, X.; Morlet-Savary, F.; Graff, B.; Fouassier, J.P.; Gigmes, D.; et al. Multicolor photoinitiators for radical and cationic polymerization: Mono vs. poly functional thiophene derivatives. Macromolecules 2013, 46, 6786-6793.

109. Xiao, P.; Dumur, F.; Graff, B.; Morlet-Savary, F.; Vidal, L.; Gigmes, D.; Fouassier, J.P.; Lalevee, J. Indanedione skeleton for the design of low intensity 300-500 nm light sensitive initiators. Macromolecules 2014, 47, 26-34.

110. Xiao, P.; Dumur, F.; Graff, B.; Morlet-Savary, F.; Gigmes, D.; Fouassier, J.P.; Lalevee, J. Tunable organophotocatalysts for polymerization reactions. Macromolecules 2014, 47, 973-978.

111. Xiao, P.; Dumur, F.; Graff, B.; Gigmes, D.; Fouassier, J.P.; Lalevee, J. Blue light sensitive naphthalic anhydride derivatives. Macromolecules 2014, 47, 601-608.

112. Xiao, P.; Dumur, F.; Graff, B.; Gigmes, D.; Fouassier, J.P.; Lalevee, J. Cationic and thiol-ene photopolymerization upon red lights using anthraquinone derivatives as photoinitiators. Macromolecules 2013, 46, 6744-6750.

113. Tehfe, M.A.; Dumur, F.; Xiao, F.; Delgove, M.; Graff, B.; Fouassier, J.P.; Gigmes, D.; Lalevee, J. Chalcone derivatives as highly versatile photoinitiators for radical, cationic, thiol-ene and IPN polymerization reactions upon visible lights. Polym. Chem. 2014, 5, 382-390.

114. Mokbel, H.; Dumur, F.; Telitel, S.; Vidal, L.; Xiao, P.; Versace, D.L.; Tehfe, M.A.; Morlet-Savary, F.; Graff, B.; Fouassier, J.P.; et al. Photoinitiating systems of polymerization and in-situ incorporation of silver nanoparticles in polymer matrixes upon visible lights: Push-pull malonate and malonitrile based dyes. Polym. Chem. 2013, 4, 5679-5687.

115. Xiao, P.; Dumur, F.; Frigoli, M.; Tehfe, M.A.; Graff, B.; Fouassier, J.P.; Gigmes, D.; Lalevee, J. Naphthalimide based methacrylated photoinitiators in radical and cationic photopolymerization under visible light. Polym. Chem. 2013, 4, 5440-5448.

116. Xiao, P.; Simonet-Jegat, C.; Dumur, F.; Schrodj, G.; Tehfe, M.A.; Fouassier, J.P.; Gigmes, D.; Lalevee, J. Silicon polyoxomolybdate $\left(\left[\mathrm{SiMo}_{2} \mathrm{O}_{40}\right]^{4-}\right)$ as photoinitiator in radical and cationic photopolymerization: Application to the fabrication of polyoxometalate/polymer hybrid materials. Polym. Chem. 2013, 4, 4526-4530.

117. Xiao, P.; Dumur, P.; Tehfe, M.A.; Graff, B.; Gigmes, D.; Fouassier, J.P.; Lalevee, J. Effect of substituents on the photoinitiating abilities of acridinediones. Macromol. Chem. Phys. 2013, 214 , 2276-2282.

118. Xiao, P.; Dumur, F.; Tehfe, M.A.; Graff, B.; Gigmes, D.; Fouassier, J.P.; Lalevee, J. Difunctional acridinediones as photoinitiators of polymerization under UV and visible lights: Structural effects. Polymer 2013, 54, 3458-3466. 
119. Xiao, P.; Dumur, F.; Tehfe, M.A.; Graff, B.; Fouassier, J.P.; Gigmes, D.; Lalevee, J. Keggin-type polyoxometalate ion $\left(\left[\mathrm{PMo}{ }_{12} \mathrm{O}_{40}\right]^{3-}\right)$ in radical initiating systems: Application to radical and cationic photopolymerization. Macromol. Chem. Phys. 2013, 214, 1749-1755.

120. Tehfe, M.A.; Dumur, F.; Graff, B.; Gigmes, D.; Fouassier, J.P.; Lalevee, J. Blue-to-red light sensitive push-pull structured photoinitiators: Indandione derivatives for radical and cationic photopolymerization reactions. Macromolecules 2013, 46, 3332-3341.

121. Telitel, S.; Ouhib, F.; Fouassier, J.P.; Jerome, G.; Detrembleur, C.; Lalevee, J. Thiophene derivatives with donor- $\pi$-acceptor structures for enhanced light-absorption properties and efficient cationic polymerization upon green-light irradiation. Macromol. Chem. Phys. 2014, 215 , 1514-1524.

122. Tehfe, M.A.; Dumur, F.; Xiao, P.; Graff, B.; Morlet-Savary, F.; Fouassier, J.P.; Gigmes, D.; Lalevee, J. New chromone based photoinitiators for polymerization reactions upon visible lights. Polym. Chem. 2013, 4, 4234-4244.

123. Tehfe, M.A.; Dumur, F.; Graff, B.; Gigmes, D.; Fouassier, J.P.; Lalevee, J. Green light induced cationic ring opening polymerization reactions: Perylene bis-dicarboximides as efficient photosensitizers. Macromol. Chem. Phys. 2013, 214, 1052-1060.

124. Tehfe, M.A.; Dumur, F.; Contal, E.; Graff, B.; Morlet-Savary, F.; Gigmes, D.; Fouassier, J.P.; Lalevee, J. New insights in radical and cationic polymerization upon visible light exposure: Role of novel photoinitiator systems based on the pyrene chromophore. Polym. Chem. 2013, 4, 1625-1634.

125. Tehfe, M.A.; Dumur, F.; Telitel, S.; Gigmes, D.; Contal, E.; Bertin, D.; Morlet-Savary, F.; Graff, B.; Fouassier, J.P.; Lalevee, J. Metal based photoinitiators: A new progress using zinc complexes. Eur. Polym. J. 2013, 49, 1040-1049.

126. Tehfe, M.A.; Zein-Fakih, A.; Lalevee, J.; Dumur, F.; Gigmes, D.; Graff, B.; Morlet-Savary, F.; Hamied, T.; Fouassier, J.P. Pyridinium salts: New systems for photopolymerization reactions upon visible light exposure. Eur. Polym. J. 2013, 49, 567-574.

127. Telitel, S.; Lalevee, J.; Blanchard, N.; Kavalli, T.; Tehfe, M.A.; Schweitzer, S.; Morlet-Savary, F.; Graff, B.; Fouassier, J.P. Photopolymerization of cationic monomers and acrylate/divinylether blends under visible lights using pyrromethene dyes. Macromolecules 2012, 45, 6864-6868.

128. Tehfe, M.A.; Dumur, F.; Graff, B.; Morlet-Savary, F.; Fouassier, J.P.; Gigmes, D.; Lalevee, J. Trifunctional photoinitiators based on a triazine skeleton for visible light sources and UV LED induced polymerizations. Macromolecules 2012, 45, 8639-8647.

129. Tehfe, M.A.; Ma, L.; Graff, B.; Morlet-Savary, F.; Fouassier, J.P.; Zhao, J.; Lalevee, J. Cyclometallated Pt(II) complexes in visible light photoinitiating systems. Macromol. Chem. Phys. 2012, 213, 2282-2286.

130. Tehfe, M.A.; Lalevee, J.; Telitel, S.; Contal, E.; Dumur, F.; Gigmes, D.; Bertin, D.; Nechab, M.; Graff, B.; Morlet-Savary, F.; et al. Polyaromatic structures as organophotocatalysts for efficient dual radical/cationic photopolymerizations under visible lights. Macromolecules 2012, 45, 4454-4460.

131. Lalevee, J.; Blanchard, N.; Tehfe, M.A.; Peter, M.; Morlet-Savary, F.; Gigmes, D.; Fouassier, J.P. Efficient dual radical/cationic photoinitiator under visible lights: A new concept. Polym. Chem. 2011, 2, 1986-1991. 
132. Tehfe, M.A.; Lalevee, J.; Morlet-Savary, F.; Graff, B.; Blanchard, N.; Fouassier, J.P. Polymerization reactions under visible lights. Macromolecules 2012, 45, 1746-1752.

133. Xiao, P.; Dumur, F.; Graff, B.; Gigmes, D.; Lalevee, J. Panchromatic photopolymerizable cationic films using indoline and squaraine dye based photoinitiating systems. Macromolecules 2013, 46, 7661-7667.

134. Decker, C.; Bendaikha, T. Interpenetrating polymer networks. II. Sunlight induced polymerization. J. Appl. Polym. Sci. 1998, 70, 2269-2282.

135. Decker, C.; Nguyen Thi Viet, T.; Le Xuan, H. New systems for photopolymerization reactions upon visible light exposure. Eur. Polym. J. 1996, 32, 1319-1326.

136. Esposito Corcione, C.; Striani, R.; Frigione, M. UV-cured methacrylic-silica hybrids: Effect of oxygen inhibition on photo-curing kinetics. Thermochim. Acta 2014, 576, 47-55.

137. Esposito Corcione, C. Development and characterization of novel photopolymerizable formulations for stereolithography. J. Polym. Eng. 2014, 34, 85-93.

138. Esposito Corcione, C.; Greco, A.; Maffezzoli, A. Photopolymerization kinetics of an epoxy based resin for stereolithography. J. Therm. Anal. Calorim. 2003, 72, 687-693.

139. Esposito Corcione, C.; Greco, A.; Maffezzoli, A. Photopolymerization kinetics of an epoxy-based resin for stereolithography. J. Appl. Polym. Sci. 2004, 92, 3484-3491.

140. Esposito Corcione, C.; Greco, A.; Maffezzoli, A. Time-temperature and time-irradiation intensity superposition for photopolymerization of an epoxy based resin. Polymer 2005, 46, 8018-8027.

(C) 2014 by the authors; licensee MDPI, Basel, Switzerland. This article is an open access article distributed under the terms and conditions of the Creative Commons Attribution license (http://creativecommons.org/licenses/by/4.0/). 